\title{
Nutrient availability alters levels of non-translationally synthesized nitrogen-rich dipeptides in Emiliania huxleyi
}

\author{
Hyun-su Kim ${ }^{1,2}$, Michael J. Walsh ${ }^{1}$, Huijun Yang $^{1}$, Beth A. Ahner ${ }^{1, *}$ \\ ${ }^{1}$ Biological and Environmental Engineering, Riley-Robb Hall, Cornell University, Ithaca, New York 14853, USA \\ ${ }^{2}$ Present address: Dept. of Earth and Environmental Sciences, Jeonbuk National University, Jeonju, Jeonbuk 561-756, Korea
}

\begin{abstract}
The coccolithophore Emiliania huxleyi synthesizes the N-rich dipeptides glutaminecysteine (gln-cys) and arginine-cysteine (arg-cys) in response to metal stress, but it is unknown how these compounds are synthesized and whether these dipeptides may also be involved in $\mathrm{N}$ assimilation or $\mathrm{N}$ storage. Accumulation of dipeptides and other reduced thiols was much greater in P-limited than N-limited batch cultures, and levels of dipeptide and cysteine were higher in an open-ocean strain compared to a coastal isolate. A comparison of dipeptide concentration to total N, protein, and amino acid content of $\mathrm{N}$ - and P-limited batch cultures of both strains was used to yield clues about strain-specific differences in nitrogen storage. Both gln-cys and arg-cys quickly accumulated following the addition of nitrate or ammonium to N-limited batch cultures. Accumulation of dipeptides was not suppressed by the ribosomal inhibitor cycloheximide, except at the earliest time point following ammonium addition, and, after $24 \mathrm{~h}$, the inhibitor had either no effect on intracellular concentrations or instead enhanced accumulation. Results suggest that accumulation of dipeptides does not require de novo synthesis of protein and that an enzymatic pathway is responsible for synthesis. Rapid degradation of intracellular gln-cys and arg-cys was observed following the addition of phosphate to P-limited batch cultures. Possible synthetic pathways and ties to $\mathrm{N}$ metabolism are discussed.
\end{abstract}

KEY WORDS: Dipeptide synthesis · Nitrogen storage $\cdot$ Emiliania huxleyi Cysteine $\cdot$ Arginine Glutamine

Resale or republication not permitted without written consent of the publisher

\section{INTRODUCTION}

The coccolithophore Emiliania huxleyi is a widespread phytoplankton species that can be found in arctic to subtropical oceanic regions (Paasche 2001). Large blooms are often observed in cold coastal and oceanic regions (Brown \& Yoder 1994), and the species has been noted to have a large impact on global carbon and sulfur cycles, which, in turn, can affect climate (Holligan et al.1993). In addition to stratification and high light, a high nitrate to phosphate ratio $(>16)$ has been thought to be an important environmental driver for E. huxleyi blooms, in part, because E. huxleyi is known to have an exceptionally high affinity for phosphate uptake (Riegman et al. 2000) in addition to mul- tiple high-affinity alkaline phosphatases (Riegman et al. 2000, Dyhrman \& Palenik 2003) and a relatively low affinity for nitrate (Riegman et al. 2000). In the field, however, E. huxleyi blooms are documented frequently in waters containing low nitrate to phosphate ratios, such as in the Bering Sea where N:P ratios are typically $<10$ (Lessard et al. 2005). It is therefore important to investigate potentially unique aspects of nitrogen metabolism in E. huxleyi in order to understand its ecological success.

Nitrogen assimilation in Emiliania huxleyi has been shown to proceed via the standard glutamine synthetase (GS) pathway, and the 2 identified isoforms of GS do not appear to be substantially different from others found in marine phytoplankton, though 1 iso- 
form exhibited a fairly high $K_{\mathrm{m}}$ for $\mathrm{NH}_{4}{ }^{+}$in biosynthetic assays (Maurin \& Le Gal 1997). In addition, E. huxleyi has been shown to utilize many sources of dissolved organic nitrogen (DON), such as small-chain aliphatic amides and urea (Palenik \& Henson 1997).

Nitrogen storage mechanisms have been hypothesized as a means for algae to take advantage of a variable nitrogen supply, such as during an upwelling event (e.g. Dortch et al. 1984). Several clones of Emiliania huxleyi have been shown to contain high intracellular concentrations of the N-rich thiol-containing dipeptides arginine-cysteine (arg-cys) and glutaminecysteine (gln-cys), discovered as part of a Cu-stressresponse system (Dupont et al. 2004). Intracellular concentrations of these dipeptides varied during the growth of batch cultures (Dupont \& Ahner 2005) and increased upon nitrogen addition (Dupont et al. 2004). This led the authors to hypothesize that these compounds were linked to a nitrogen storage mechanism in E. huxleyi, perhaps in a manner analogous to multiL-arginyl-poly-L-aspartate (also known as cyanophycin), which serves as a nitrogen storage mechanism for some phototrophic prokaryotes (e.g. Allen et al. 1980).

In the present study, we specifically investigated the accumulation of these dipeptides in batch cultures of Emiliania huxleyi. We compared various measures made on $\mathrm{N}$ - and P-limited batch cultures to evaluate whether the dipeptides serve as a significant intracellular $\mathrm{N}$ storage in 2 strains of this species, 1 from the open ocean and 1 isolated from coastal waters. We measured the accumulation and degradation of these dipeptides in response to changes in nitrogen and phosphorus availability. We used a ribosomal inhibitor to investigate the synthetic pathway of the dipeptides.

\section{MATERIALS AND METHODS}

Algae strains and medium. Emiliania huxleyi Clone CCMP 373 (Strain 373) was obtained from the Provasoli-Guillard National Center for Culture of Marine Phytoplankton; this clone is listed as having been isolated from the Sargasso Sea. EH 382-1 (Strain 382-1), isolated from the California Current, was provided to us by B. Palenik and D. Landry (Scripps Institute of Oceanography). Axenic cultures of E. huxleyi were grown in synthetic seawater medium Aquil described by Price et al. (1988) with chelex-purified and filtersterilized sodium nitrate and sodium phosphate added separately at the concentrations specified for various experiments. Chemical speciation calculations were performed with MINEQL+ (Schecher \& McAvoy 1998). Cultures were grown in a controlled temperature growth chamber with a constant light source of $120 \mu \mathrm{mol}$ photons $\mathrm{m}^{-2} \mathrm{~s}^{-1}$ at $19 \pm 1^{\circ} \mathrm{C}$. Batch cultures were grown in 11 or $500 \mathrm{ml}$ acid-washed polycarbonate bottles with loosened caps, and, except for just prior to sampling, the cultures were not agitated or shaken. Growth was monitored by fluorescence (Turner Instruments) as a proxy for chlorophyll a (chl a; Brand et al. 1986). Growth rates were calculated by plotting the natural log of culture fluorescence versus time.

$\mathbf{N}$ - and P-limited batch cultures. For N-limited batch cultures, $20 \mu \mathrm{mol} \mathrm{l}^{-1}$ sodium nitrate and $10 \mu \mathrm{mol} \mathrm{l^{-1 }}$ sodium phosphate were added to Aquil prior to culture inoculation. This resulted in an $\mathrm{N}$ to $\mathrm{P}$ molar ratio of $2: 1$ in the initial medium, which is well below the $16: 1$ molar ratio of average cell biomass as defined by Redfield et al. (1963). For P-limited cultures, $300 \mu \mathrm{mol} \mathrm{l^{-1 }}$ sodium nitrate and $1 \mu \mathrm{mol} \mathrm{l}^{-1}$ sodium phosphate were added to the initial medium (N:P; 300:1). Control batch cultures were grown in standard Aquil medium containing $300 \mathrm{mmol} \mathrm{l}^{-1}$ sodium nitrate and $10 \mu \mathrm{mol} \mathrm{l^{-1 }}$ sodium phosphate, which likely becomes slightly Plimiting as the initial ratio is 30:1. For the purposes of the present paper, we defined nutrient limitation in a batch culture by the ability of nutrient addition to restore cell growth following a period of no growth. Prior to the onset of nutrient limitation, specific growth rates of Strains 373 and 382-1 were roughly from 0.6 to $0.7 \mathrm{~d}^{-1}$.

Samples for the various analyses were collected from the batch culture not more than $24 \mathrm{~h}$ after the culture fluorescence stopped increasing exponentially. Different volumes of culture (50 to $100 \mathrm{ml}$ ) were filtered onto appropriate filter types for the various analyses. Filters were stored in liquid nitrogen until processed.

Time course experiments: $\mathbf{N}$ and $\mathbf{P}$ additions. The N-limited batch cultures were grown until culture fluorescence no longer increased exponentially, at which point, for $\mathrm{N}$-addition experiments, $100 \mu \mathrm{mol} \mathrm{l}^{-1}$ sodium nitrate $\left(\mathrm{NaNO}_{3}\right)$ or $100 \mu \mathrm{mol} \mathrm{l} \mathrm{l}^{-1}$ ammonium chloride were added $(t=0 \mathrm{~h})$. Samples were collected for particulate thiols $(\sim 50 \mathrm{ml})$ and particulate chl a extractions at appropriate time points for $24 \mathrm{~h}$. For inhibitor studies, $10 \mathrm{mg} \mathrm{l}^{-1}$ cycloheximide was added concurrently with nitrate and ammonium.

Similarly, P-limited batch cultures were grown until culture fluorescence no longer increased exponentially, at which point, for P-addition experiments, $20 \mu \mathrm{mol} \mathrm{l}^{-1}$ sodium phosphate was added $(t=0 \mathrm{~h})$. Samples were collected for particulate thiols $(\sim 50 \mathrm{ml})$ and particulate chl $\mathrm{a}$ at $24 \mathrm{~h}$ intervals following P-addition for up to $120 \mathrm{~h}$ along with continued measurement of fluorescence to monitor growth.

P-limiting conditions in batch cultures were confirmed by an observation of resumed growth immediately following the addition of phosphate (Strain 373 shown in Fig. 1A) as compared to level fluorescence observed in batch cultures to which no $\mathrm{P}$ was added 
(Fig. 1A). In contrast, in vivo fluorescence did not recover immediately following $\mathrm{N}$ addition to $\mathrm{N}$-limited cultures within the time period assayed in experiments published herein, and instead a slight decrease compared to controls was often observed during the first $72 \mathrm{~h}$ following nitrate or ammonia addition (Fig. 1B). Separate preliminary grow-out experiments (shown in Fig. A1 in Appendix 1), however, revealed that ultimately $\mathrm{N}$ addition did result in a recovery of growth compared to controls after $72 \mathrm{~h}$. At $t=0 \mathrm{~h}$, the cells are physiologically similar to those collected from separate batch cultures for measurement of the various parameters described below.

Particulate chl $\boldsymbol{a}$ and cell counts. Chl $a$ was determined by filtering $5 \mathrm{ml}$ of culture onto a Whatman GF/F filter, followed by immediate extraction with $5 \mathrm{ml}$ of 45:45:10 dimethyl sulfoxide (DMSO):acetone:water (Shoaf \& Lium 1976). Following incubation in the dark for $5 \mathrm{~h}$, chl a fluorescence was measured with a fluorometer (Turner Instruments) that was externally cali-
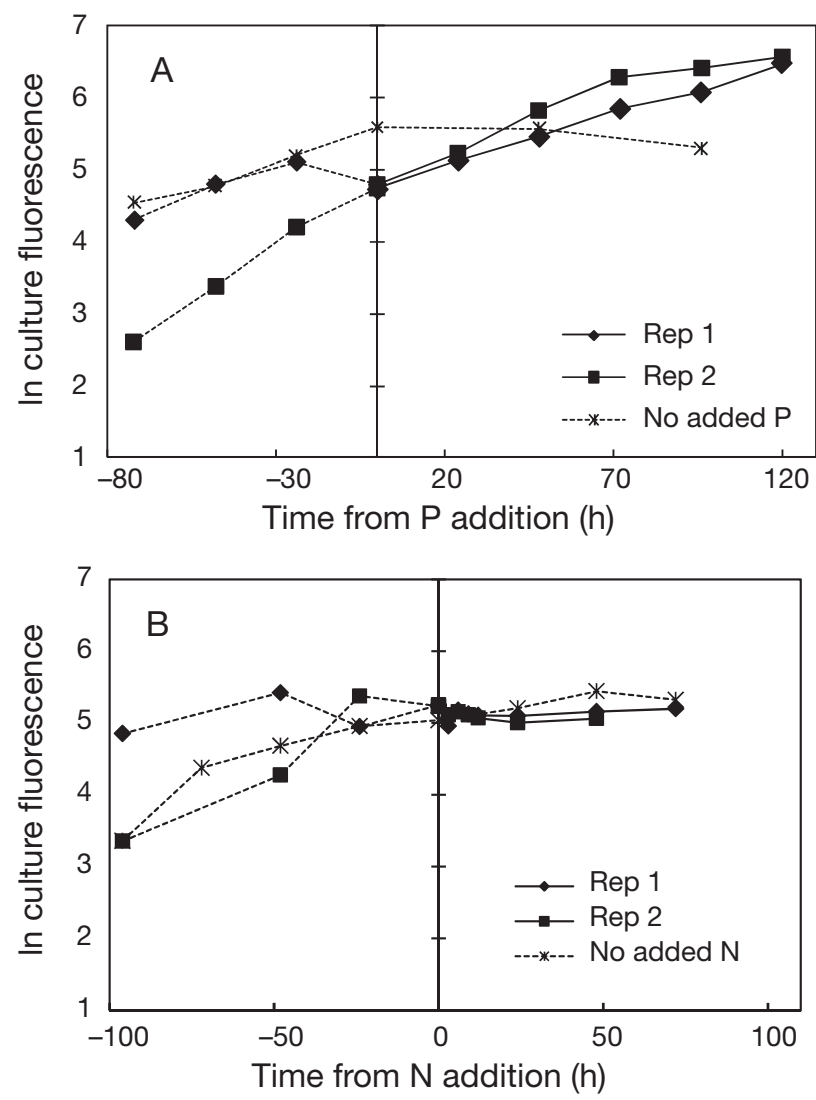

Fig. 1. Emiliania huxleyi. Plots of the natural logarithm of culture fluorescence as a function of time (A) before and after the addition of $20 \mu \mathrm{mol} \mathrm{l}^{-1}$ phosphate to replicate P-limited batch cultures of E. huxleyi Strain 373 and (B) before and after addition of $100 \mu \mathrm{mol} \mathrm{l}^{-1}$ ammonia (Rep 1) and nitrate (Rep 2) to $\mathrm{N}$-limited batch cultures of the same strain. Controls to which no $\mathrm{P}$ or $\mathrm{N}$ were added are shown in both plots continuing as dotted lines past $t=0$ brated with a spectrophotometer (Perkin-Elmer) and a chl a solution extracted from spinach with the same DMSO:acetone:water solution. Cell counts were made immediately with a Levy hemacytometer (Hausser Scientific Company).

Total N, protein, and amino acid analysis. For nitrogen and carbon analysis, algal cells were collected on $25 \mathrm{~mm}$ glass fiber filters (GF/F; Whatman), dried in a $60^{\circ} \mathrm{C}$ oven for $2 \mathrm{~d}$, and analyzed with a CE Elantech Inc Flash EA $1112 \mathrm{CN}$ analyzer.

For amino acid analysis, cells were collected on FP450 vertical membranes $\left(0.45 \mu m_{i}\right.$ Pall Life Sciences), and filters were shipped on dry ice to the University of Nebraska Medical Center Protein Structure Core Facility, where they were hydrolyzed in a liquid mix of $6 \mathrm{~N} \mathrm{HCl}, 1 \%$ phenol, and $0.5 \%$ sodium sulfite for $20 \mathrm{~h}$ at $110^{\circ} \mathrm{C}$. Samples were dried and then redissolved in $200 \mu \mathrm{l} 0.02 \mathrm{~N} \mathrm{HCl}$. Injections of $50 \mu \mathrm{l}$ were made onto a Hitachi amino acid analyzer. Norleucine was added as an internal standard to correct for dilution errors. Blank filters, through which spent seawater medium was passed, were also analyzed and used to correct data. Hydrolysis results in the destruction of cysteine and the conversion of glutamine and asparagine into glutamic and aspartic acid, respectively. Therefore, the sum of the amino acids glutamate and glutamine is reported as Glx and of asparagine and aspartic acid is reported as Asx. For the purpose of calculating total $\mathrm{N}$ in amino acids, it was assumed arbitrarily that each amino acid accounted for half of the total.

Total cellular protein was measured with a standard Bradford Assay Kit (Thermo Scientific). FP-450 vertical membrane filters, each containing $25 \mathrm{ml}$ of filtered culture, were homogenized in $100 \mathrm{mM}$ Tris buffer, $\mathrm{pH} 7.1$, using a VirSonic60 sonication probe. Samples were homogenized for four $30 \mathrm{~s}$ intervals in an ice-water bath to prevent overheating. The Bradford Coomassie reagent was added to an aliquot of the homogenate immediately after sonication. After $10 \mathrm{~min}$, absorbance measurements were taken using a Perkin Elmer Lambda EZ201 spectrophotometer. Bovine serum albumin was used to generate a standard curve.

Particulate thiols. Cells were collected by gently $(<50 \mathrm{kPa})$ filtering 50 to $100 \mathrm{ml}$ of culture onto a $25 \mathrm{~mm}$ Whatman GF/F filter that was stored immediately in liquid nitrogen until processing. Upon removal from liquid nitrogen, the filters were immediately heated in $2 \mathrm{ml}$ of $10 \mathrm{mmol} \mathrm{l}^{-1}$ methanesulfonic acid (MSA) for 3 min before homogenization with a Wheaton overhead stirrer in an ice-water bath for 3 min. The slurry was then centrifuged for $15 \mathrm{~min}$ at $16000 \times \mathrm{g}$ at $4^{\circ} \mathrm{C}$ (Biofuge Fresco, Heraeus Instruments). To an aliquot of supernatant $(800 \mu \mathrm{l}), 3 \mu \mathrm{l}$ of $15 \mathrm{mmol} \mathrm{l}^{-1}$ dithiothreitol (DTT; Shelton Scientific) was added to achieve a final concentration of $50 \mu \mathrm{mol} \mathrm{l}^{-1}$. Addition of $84 \mu \mathrm{l}$ of 
$100 \mathrm{mmol} \mathrm{l}^{-1}$ tetraborate buffer $\left(8.8 \mathrm{mmol}^{-1}\right.$ final concentration) that also contained $10 \mathrm{mmol}^{-1}$ diethylenetriaminepentaacetic acid (DTPA; $880 \mu \mathrm{mol} \mathrm{l^{-1 }}$ final concentration) was then made to adjust $\mathrm{pH}$ to 9. After $10 \mathrm{~min}, 3 \mathrm{\mu l}$ of the fluorescent probe monobromobimane $\left(50 \mathrm{mmol} \mathrm{l}^{-1}\right.$ in acetonitrile, $\mathrm{mBBr}$; Molecular

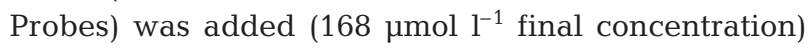
(Ahner et al. 2002). After vortexing, the samples were incubated at room temperature in the dark for $10 \mathrm{~min}$ after which $60 \mu \mathrm{l}$ of $800 \mathrm{mmol} \mathrm{l}^{-1}$ MSA was added to acidify the sample. Particulate thiol concentrations were then normalized to particulate chl a or to cell number as specified.

HPLC thiol analysis. Monobromobimane-derivatized samples were analyzed by high-performance liquid chromatography (HPLC; Beckman) equipped with a Supelco Discovery reverse-phase C-16 amide column $(4.6 \times 250 \mathrm{~mm})$ and a $100 \mu \mathrm{l}$ injection loop. Compounds were quantified postcolumn by fluorescence detection (Gilson, excitation 310 to $410 \mathrm{~nm}$, emission 475 to $650 \mathrm{~nm}$ ). Solution A was a phosphate buffer containing $25 \mathrm{mmol} \mathrm{l}^{-1} \mathrm{KH}_{2} \mathrm{PO}_{4}$ titrated to $\mathrm{pH} 3.5$ by $30 \%$ $o$-phosphoric acid $\left(\mathrm{H}_{3} \mathrm{PO}_{4}\right)$, and solution $\mathrm{B}$ was pure acetonitrile. The elution gradient was as follows: $8 \% \mathrm{~B}$ for $2 \mathrm{~min}$; a series of linear increases to 12.5, 16.4, 18.4, 40 , and $80 \%$ over $10,2.7,10.3,6$, and $3 \mathrm{~min}$, respectively; $80 \%$ B for 2 min; a linear decrease to $8 \%$ B over $1 \mathrm{~min}$; and a final $3 \mathrm{~min}$ at $8 \% \mathrm{~B}$ to re-equilibrate the column (Method $C_{i}$ Wei et al. 2003). The flow rate was $1 \mathrm{ml} \mathrm{min}^{-1}$. Standards of arg-cys, gln-cys (Cell Essentials), cysteine, and glutathione (GSH; SigmaAldrich) were analyzed in order to verify retention times and to develop standard curves for peak area calibration. For all the various thiols, the detection limit of the method is about $5 \mathrm{nmol} \mathrm{l}^{-1}$ using a $200 \mu \mathrm{l}$ injection loop.
Statistical analyses. A Student's $t$-test calculator was used to compare data sets. The threshold for statistically significant differences was arbitrarily set at $\mathrm{p}<0.05$.

\section{RESULTS}

\section{N- and P-limited batch cultures}

The concentrations of all 4 measured thiols, including the N-rich dipeptides, were significantly higher in P-limited batch cultures of the open-ocean Emiliania huxleyi isolate (Strain 373) than in N-limited batch cultures (Fig. 2A). In control cultures (with a starting N:P ratio midway between $\mathrm{N}$ - and P-limited media), we measured concentrations of GSH and cysteine that were indistinguishable from those of the P-limited cultures, whereas levels of gln-cys were indistinguishable from those measured in the N-limited cultures. The arg-cys concentration measured in the control cultures was intermediate between the P- and N-limited cultures. For the coastal isolate (Strain 382-1), statistically significant differences between $\mathrm{N}$ - and P-limited batch cultures were also observed for all thiol concentrations except GSH (Fig. 2B). Control cultures were not prepared for this strain.

Relative to intracellular GSH, typically the most abundant intracellular sulfide, concentrations of the dipeptide thiols and cysteine in the P-limited batch culture of Strain 373 were on average 6 times higher (Fig. 2A). In contrast, the concentrations of these thiols were quite similar to that of GSH in P-limited cultures of Strain 382-1 (Fig. 2B). Average concentrations of both dipeptides were higher in the open-ocean strain 373 compared to the coastal isolate 382-1 ( $p<0.05$ using a Student's $t$-test). For both species, the standard
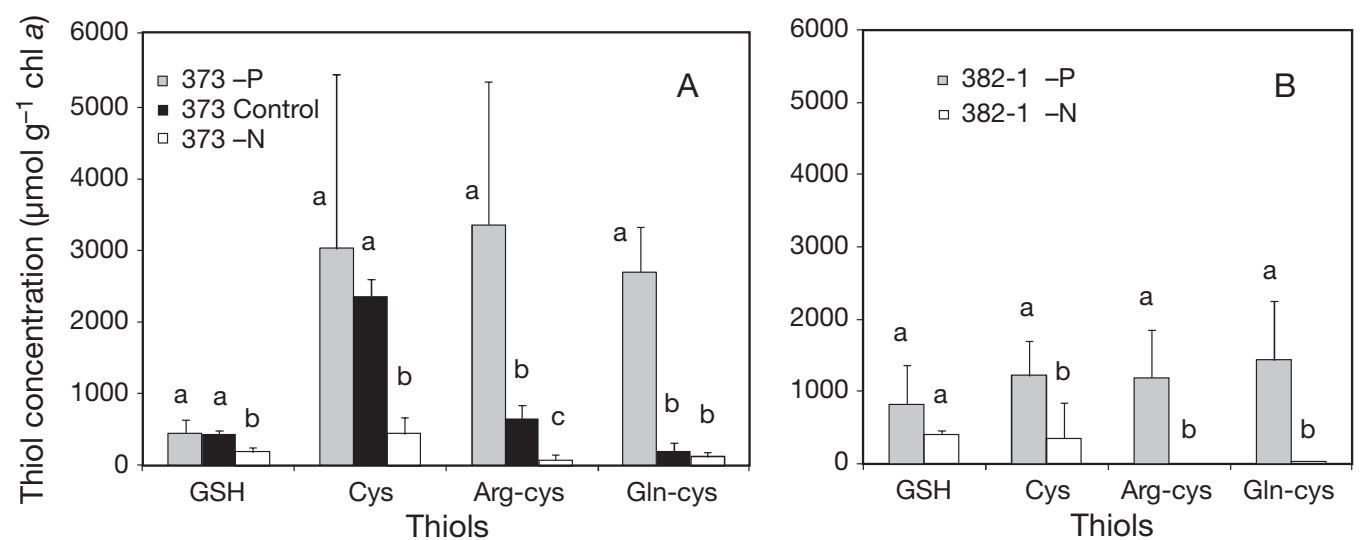

Fig. 2. Emiliania huxleyi. Thiol concentrations in batch cultures of E. huxleyi Strain 373 (A) and Strain 382-1 (B). Grey bars represent P-limited cultures; white bars are N-limited cultures. Controls for Strain 373 are shown as black bars. Replication was as follows: $\mathrm{n}=5$ for both P-limited strains and for N-limited 373, and $\mathrm{n}=3$ for N-limited 382-1 and for 373 controls. Error bars = standard deviations. Average thiol concentrations that are statistically different from each other as a result of culture treatment are labeled with different lower case letters (Student's $t$-test, $\mathrm{p}<0.05)$. GSH: glutathione; cys: cysteine; arg-cys: arginine-cysteine; gln-cys: glutamine-cysteine 
deviations among measurements of replicate cultures were very high (Fig. 2). Average concentrations of gln-cys for Strains 373 and 382-1 were $2700 \pm 630$ and $1400 \pm 820 \mathrm{mmol} \mathrm{g}^{-1} \mathrm{chl} a$, respectively, and concentrations of arg-cys were $3400 \pm 2000$ and $1200 \pm 650 \mu \mathrm{mol}$ $\mathrm{g}^{-1} \mathrm{chl} a$, respectively. Much of the variability is attributable to the difficulty of sampling the batch cultures at exactly the same degree of limitation each time the experiment is replicated; samples from replicate cultures prepared in parallel exhibit much less variability.

Average GSH concentrations were not altered as much by $\mathrm{N}$ and $\mathrm{P}$ limitation as the other thiols in these batch cultures; they varied about 2-fold and were only statistically different across treatments for Strain 373. However, the concentrations shown in Fig. 2 are all normalized to total extracted chl $a$. Given that the chl $a$ per cell is about 4 times higher in P-limited cells, this potentially translates to an 8-fold higher moles per cell GSH concentration in P-limited cells. Normalization of measurements to cell number can also be problematic if cells are getting significantly smaller under N limitation (thereby altering the cellular volume and therefore the cellular concentration), and we were not able to measure cell size. It is our objective to emphasize here that the large differences observed between treatments for the rest of the thiols would be further accentuated (not reduced) by a more appropriate normalization, but for comparison purposes between the 2 strains, we conservatively chose to normalize our measurements to chl a since this is what is typically done with field samples (Dupont et al. 2006).

An additional suite of measurements was performed on a subset of the replicate batch cultures to determine whether the high concentrations of dipeptides were playing a significant role in nitrogen storage when a large excess of $\mathrm{N}$ was available to the cells (i.e. in Plimited batch cultures). Table 1 presents a summary of these analyses, including chl $a$, protein, total $\mathrm{N}$, and arginine, all normalized per cell for comparison purposes within 1 culture replicate.

Large differences in most parameters were observed between $\mathrm{N}$ - and P-limited batch cultures. In both strains, chl a per cell was nearly 4 times greater in P- limited cells than in N-limited cells (as noted earlier and shown in Table 1). Total $\mathrm{N}$ per cell was also 4 times higher in P-limited cells compared to N-limited cells. Furthermore, P-limited cells of Strain 373 contained more than twice the protein per cell than N-limited cells. The C:N ratios were 3.1 and 4.5 times higher in N-limited cells compared to P-limited cells for Strains 373 and 382-1, respectively, a change consistent with decreasing calcification under $\mathrm{P}$ limitation (Paasche 2001). The total $\mathrm{N}$ in arg-cys and gln-cys in P-limited batch cultures of Strain 373 was 1.5 and $1.4 \%$ of the total cellular $\mathrm{N}$, respectively, for a total of close to $3 \%$ (Table 1), whereas, in the P-limited Strain 382-1, the N in these dipeptides accounted for $<0.5 \%$ of the total $\mathrm{N}$. In $\mathrm{N}$-limited cells the percentage of $\mathrm{N}$ in the dipeptides was extremely low: 0.02 and $0.01 \%$ for Strains 373 and 382-1, respectively.

Individual amino acid concentrations in $\mathrm{N}$ - and $\mathrm{P}$ limited cells are shown in Fig. A2 in Appendix 1. Due to the high cost of the amino acid analysis, only the P-limited culture analyses were replicated. In both strains, individual amino acid concentrations increased from $\mathrm{N}$ - to P-limiting conditions, but some increased more than others. On average, amino acid concentrations increased by a factor of $1.9 \pm 0.53$ and $2.8 \pm 1.3$ in Strains 373 and 382-1, respectively, consistent with the doubling of cellular protein. In the case of Strain 373, the only amino acids that increased by a factor exceeding the average by a statistically significant margin were arginine and Glx. On average, the levels of arginine and Glx acids were 3.3 and 2.9 times higher in P-limited cells (compared to the average increase of $1.9 ; \mathrm{p}<0.05$ in a Student's $t$-test). For Strain 382-1, the only amino acids that increased by a ratio significantly greater than the average were Asx and Glx (5.8 and 5.6 times higher compared to an average increase of $2.8)$; arginine increased by an average factor of 4.7 , for which the $t$-test was inconclusive $(\mathrm{p}=0.06)$. The increase in arginine attributable to the accumulation of the dipeptide arg-cys (both reported per cell in Table 1) in P-limited Strain 373 cells was $27 \pm 2 \%$, whereas, in P-limited Strain 382-1 cells, the fraction was only $7.4 \pm 1 \%$. A similar calculation is not possible

Table 1. Emiliania huxleyi. Cellular content of E. huxleyi from individual batch cultures under both N-and P-limiting conditions $\left(-N_{1}-P\right)$. Gln: glutamine; cys: cysteine; arg:arginine; na: not available. Numbers in parentheses are the calculated contributions of each dipeptide to the total $\mathrm{N}$ reported as a percent. Each mole of gln-cys contains 3 moles of $\mathrm{N}$, and each mole of arg-cys contains 5 moles of $\mathrm{N}$

\begin{tabular}{|lcccccccc|}
\hline Strain, treatment & $\begin{array}{c}\text { Chl a } \\
\left(\text { pg cell }^{-1}\right)\end{array}$ & $\begin{array}{c}\text { Protein } \\
\left(\text { pg cell }^{-1}\right)\end{array}$ & $\begin{array}{c}\mathrm{C}: \mathrm{N} \\
(\mathrm{mol}: \mathrm{mol})\end{array}$ & $\begin{array}{c}\mathrm{N} \\
\left(\mathrm{fmol} \mathrm{cell}^{-1}\right)\end{array}$ & $\begin{array}{c}\text { Gln-cys } \\
\left(\text { amol cell }^{-1}\right)\end{array}$ & $\begin{array}{c}\text { Arg-cys } \\
\left(\text { amol cell }^{-1}\right)\end{array}$ & $\begin{array}{c}\text { Arg } \\
\left(\mathrm{fmol} \mathrm{cell}^{-1}\right)\end{array}$ & $\begin{array}{c}\text { Arg } \\
(\% \text { total N})\end{array}$ \\
\hline $373,-\mathrm{N}$ & 0.044 & 1.9 & 20 & 28.4 & $5.0(0.05 \%)$ & $1.3(0.02 \%)$ & 1.0 & 14.2 \\
$373,-\mathrm{P}$ & 0.17 & 5.0 & 6.4 & 113 & $541(1.4 \%)$ & $345(1.5 \%)$ & 2.8 & 9.9 \\
$382-1,-\mathrm{N}$ & 0.025 & na & 27 & 24.7 & $1.1(0.01 \%)$ & $0.54(0.01 \%)$ & 0.73 & 11.8 \\
$382-1,-\mathrm{P}$ & 0.097 & 5.9 & 6.0 & 121 & $68(0.17 \%)$ & $75(0.31 \%)$ & 2.9 & 9.6 \\
\hline
\end{tabular}


for gln-cys because of the unknown proportion glutamate and glutamine contributing to the total Glx measurement.

\section{N-addition time courses}

N-limited batch cultures of Strain 373 were also used to examine the physiological response over time following the addition of nitrate or ammonium to the culture. In general, concentrations of gln-cys and arg-cys increased with time over the $24 \mathrm{~h}$ of sampling, with ammonium causing a more immediate increase in glncys (at $t=2 \mathrm{~h}$ ), whereas gradual increases were observed over $24 \mathrm{~h}$ with the addition of nitrate (Fig. 3A). Slower accumulation and lower concentrations of argcys were observed upon addition of both $\mathrm{N}$ forms (Fig. 3B, note the difference in scale between Panels B and A). In $24 \mathrm{~h}$, arg-cys and gln-cys concentrations did not reach the average levels observed in P-limited batch cultures (Fig. 2A). This may reflect the fact that $\mathrm{N}$ additions were not sufficient to completely reverse the N-limiting conditions of the batch culture, since $\mathrm{N}$ :P ratios following additions were 12:1, still below the Redfield ratio of $16: 1$ and much below the 300:1 ratio used in the P-limited batch cultures. Concentrations were observed to decrease after $24 \mathrm{~h}$, suggestive of a return to a N-limited state (data not shown).

Cycloheximide was added simultaneously with $\mathrm{N}$ to determine whether the dipeptides were formed as a result of ribosomal protein translation or by an enzymatic reaction. Accumulation of gln-cys was not suppressed by the ribosomal inhibitor cycloheximide, except at the earliest time point following ammonium addition (Fig. 3A). On the contrary, the concentrations of gln-cys in response to both nitrate and ammonium in the presence of the inhibitor increased linearly with time and at many time points exceeded the concentrations observed in the corresponding $\mathrm{N}$-addition experiments without added inhibitor. The largest difference was observed at $24 \mathrm{~h}$ with ammonium addition, where the average concentration in the presence of the inhibitor was 4 times greater than without. Similarly, the levels of arg-cys increased linearly over time in the presence of the inhibitor, with both ammonium and nitrate addition, and, after $24 \mathrm{~h}$, the average concentration in the presence of the inhibitor was 3 times greater when ammonium was used as the $\mathrm{N}$ source (Fig. 3B). For both thiols, final accumulation levels were insensitive to the presence of the inhibitor when nitrate was used as the $\mathrm{N}$ source (Fig. 3A,B).

In contrast, the addition of the inhibitor appeared to suppress increases in GSH concentration. In general, initial GSH levels were higher than the initial dipeptide concentrations in the $\mathrm{N}$-limited cultures and
GSH remained relatively stable following $\mathrm{N}$ addition (Fig. 3C). In both nitrate and ammonium amended cultures, the average GSH concentrations were about double their initial values after $24 \mathrm{~h}$, whereas in the presence of the inhibitor they did not change significantly. The inhibitor may have been preventing up-regulation of the GSH biosynthetic pathway. Large differences were observed between many of the repli-
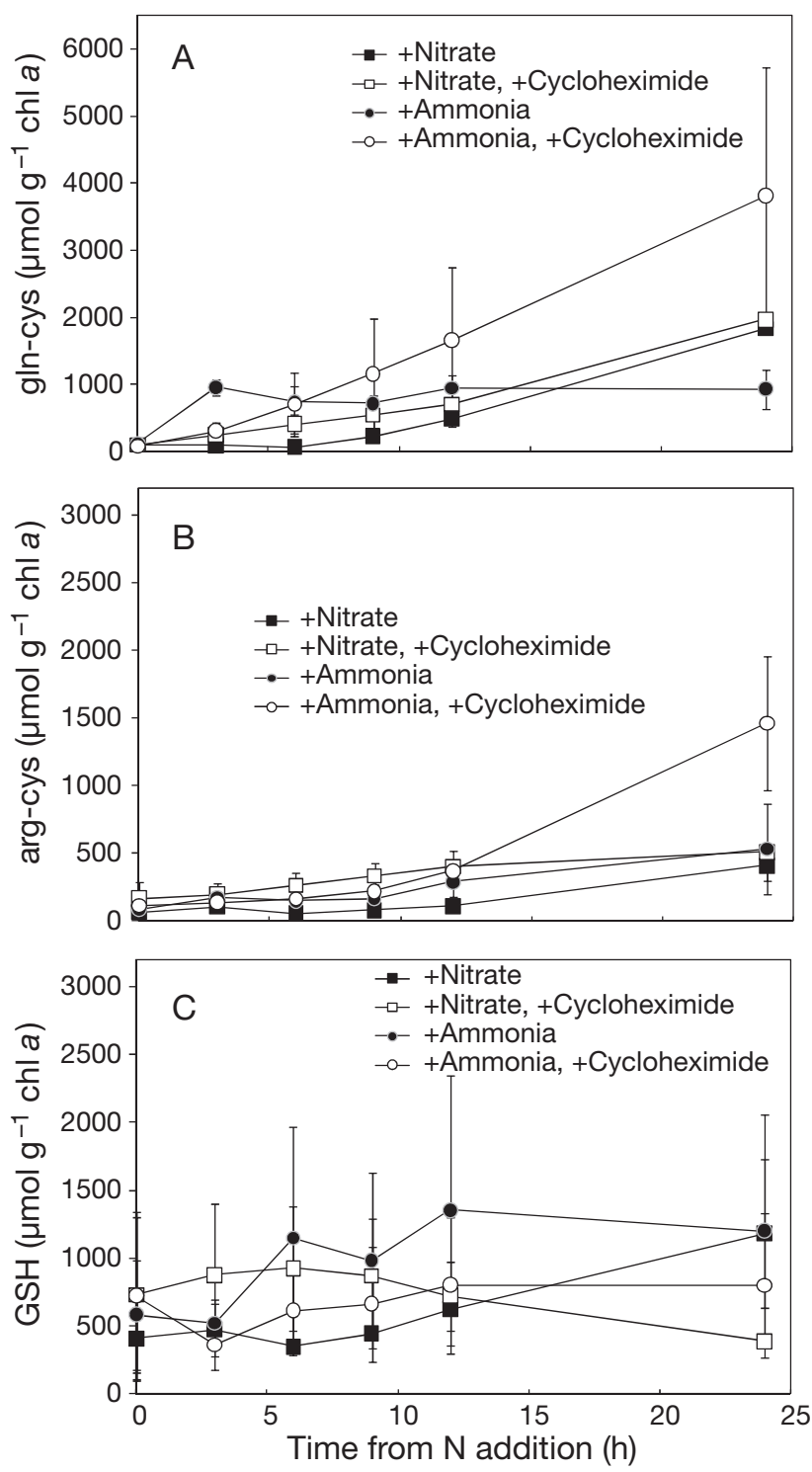

Fig. 3. Emiliania huxleyi. Thiol concentrations in E. huxleyi Strain 373, as a function of time following the addition of $100 \mu \mathrm{M}$ nitrate or ammonium with and without the addition of the inhibitor cycloheximide. (A) Glutamine-cysteine (gln-cys), (B) arginine-cysteine (arg-cys), and (C) glutathione (GSH). Replicate experimental data points were averaged, and the error bars represent the range of the measured values. Average concentrations of gln-cys and arg-cys at $24 \mathrm{~h}$ are not statistically different between treatments $(p>0.05$, Student's $t$-test) due to the large differences between replicates 
cate time points, which we again attribute to the fact that replicate cultures were not prepared in parallel.

\section{P-addition time course}

Time course experiments were also performed to examine the dynamics of gln-cys and arg-cys concentrations in P-limited batch cultures of both Emiliania huxleyi strains following phosphate addition. For Strain 382-1, gln-cys and arg-cys concentrations decreased linearly over the course of $48 \mathrm{~h}$ until the concentrations were depleted (Fig. 4B). In Strain 373, neither dipeptide decreased in concentration during the first $24 \mathrm{~h}$, and, in fact, in 1 replicate arg-cys actually went up by about $50 \%$ (Fig. 4A). GSH, in contrast, remained relatively constant in Strain 373 (Fig. 4A),

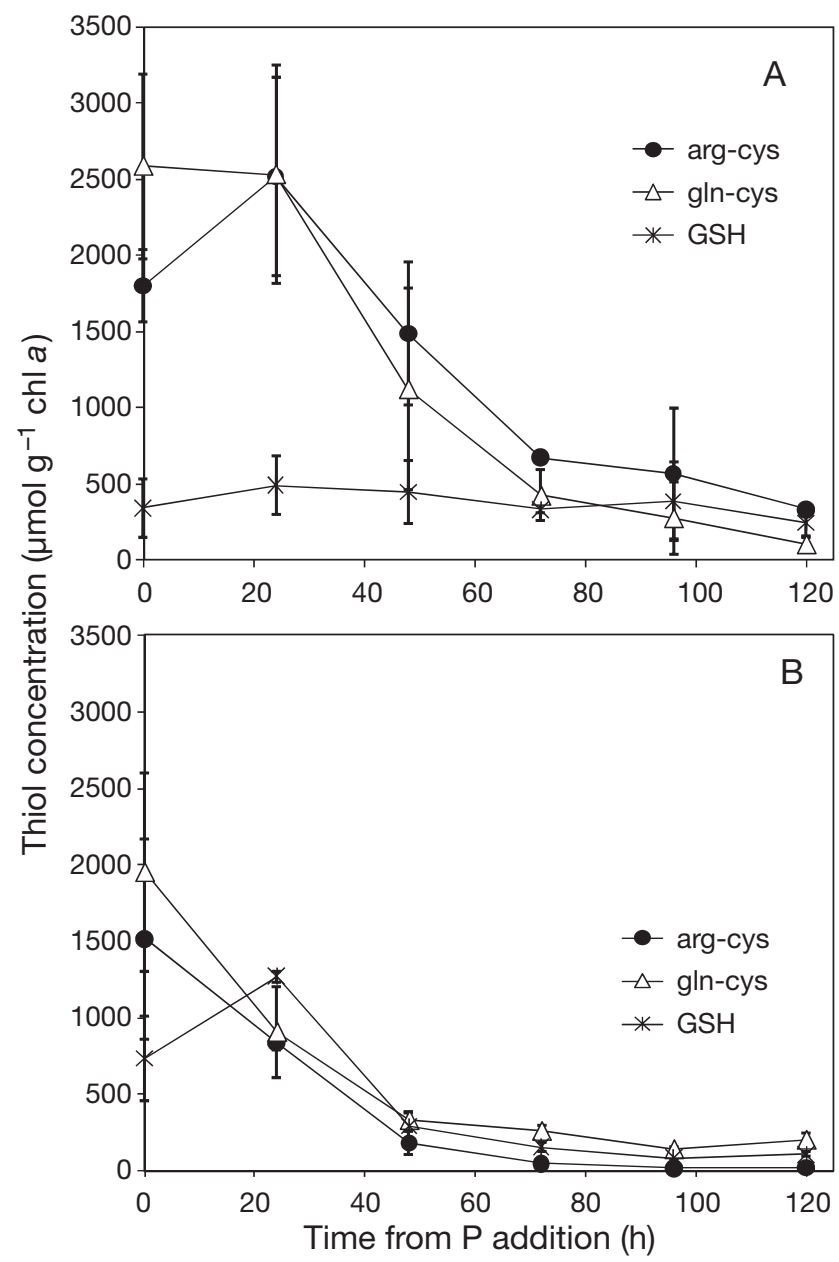

Fig. 4. Emiliania huxleyi. Thiol concentrations in E. huxleyi Strain 373 (A) and Strain 382-1 (B), following the addition of $20 \mu \mathrm{M}$ sodium phosphate to P-limited batch cultures. Replicate experimental data points were averaged, and the error bars represent the range of the measured values. Arg-cys: argininecysteine; gln-cys: glutamine-cysteine; GSH: glutathione whereas in Strain 382-1 it decreased along with the dipeptides following a peak at the $24 \mathrm{~h}$ time point (Fig. 4B). For the replicates of Strain 373 shown in Fig. 4A, one culture was caught very close to the end of exponential growth and the other had stopped growing for at least $24 \mathrm{~h}$ (Fig. 1A). Both replicates resumed exponential growth upon addition of $\mathrm{P}$ without any substantial lag (Fig. 1A). At the conclusion of this experiment, the cells are expected to be slightly N-limited (added ratio of $\mathrm{N}: \mathrm{P}=15: 1$ ), which is consistent with the low values of arg-cys and gln-cys measured at the $120 \mathrm{~h}$ time point.

\section{DISCUSSION}

The accumulation of gln-cys and arg-cys in Emiliania huxleyi following the resupply of nitrogen to $\mathrm{N}$ limited batch cultures, as well as the high levels of accumulation in P-limited batch cultures, suggest some role of these dipeptides in nitrogen assimilation and/or storage. The immediate accumulation of glncys in response to added ammonium is consistent with reports of rapid ammonium uptake and assimilation under N-limiting conditions (Dortch et al. 1984) with a slower response to nitrate. Accumulation of arg-cys was not as rapid and was relatively insensitive to the form of $\mathrm{N}$ added. Nitrogen would also appear to be rapidly mobilized from the dipeptides when $\mathrm{P}$ limitation is relieved. Strain-specific differences are observed and may be due to genetic variability arising from contrasting habitat pressures.

The rapid accumulation of gln-cys upon addition of ammonium as compared to nitrate in Strain 373 (Fig. 3A) may be due to the distinctly different biosynthetic pathways leading to the incorporation of ammonia and nitrate into amino acids. Incorporation of ammonia into amino acids proceeds primarily via the action of GS, which generates glutamine from glutamate (Inokuchi et al. 2002). There are at least 2 isoforms of GS in Emiliania huxeyi, one that is cytosolic and another that is localized in the chloroplast (Maurin \& Le Gal 1997, Bruhn et al. 2010). The cytosolic GS is thought to dominate exogenous ammonium assimilation as well as re-assimilation of ammonia liberated during the catabolism of proteins and other organic nitrogen compounds, whereas the chloroplastic isoform is responsible for ammonia assimilation following reduction of nitrate and the re-assimilation of ammonia liberated during photorespiration. The production of gln-cys following synthesis of glutamine potentially decreases inhibition of GS by free amino acids that may accumulate if protein synthesis is initially slower than amino acid synthesis. It may be that this is particularly important when the cells are provided ammo- 
nium, as the cytosolic GS may be more susceptible to feedback inhibition than the chloroplastic GS (Maurin \& Le Gal 1997). This function is supported by our observation of greater gln-cys accumulation in response to ammonium addition in the presence of a cytosolic ribosomal inhibitor compared to controls in which protein synthesis proceeds normally (Fig. 3A). Providing urea as a nitrogen source to Strain 373 resulted in a similar immediate increase in gln-cys (M. J. Walsh unpubl. data).

Likewise, the biosynthesis of arg-cys may serve to decrease product feedback inhibition of arginine synthesis in Emiliania huxleyi. The first steps in arginine biosynthesis are catalyzed by the enzymes $\mathrm{N}$-acetylglutamate synthase (NAGS) and N-acetylglutamate kinase (NAGK) (see review by Slocum 2005). Both of these enzymes are inhibited by arginine (Min et al. 2008), though some organisms have a form of NAGK that is insensitive to this inhibition. Sensitive forms of NAGK can be re-activated in the presence of arginine by PII (Chen et al. 2005), which makes storage of nitrogen in arginine possible (Llacer et al. 2007). PII is a highly conserved signal transduction protein used to regulate enzymatic pathways involved in both $\mathrm{N}$ and $\mathrm{C}$ metabolism. PII has been shown to regulate NAGK activity in photosynthetic prokaryotes that accumulate cyanophycin (Maheswaran et al. 2006). While the genomes of higher plants, red algae, green algae, and bacteria (including the photosynthetic prokaryotes Synechococcus and Prochlorococcus) all contain a gene for PII, this gene does not appear in the EST (expressed sequence tag) databases available for E. huxleyi. A gene for PII does not appear in the genomes of the marine diatoms Thalassiosira pseudonana and Phaeodactylum tricornutum either. As with gln-cys, the greater accumulation of arg-cys in the presence of a ribosome inhibitor supports a role of the dipeptide in the storage of arginine when protein synthesis is inhibited (Fig. 3B).

The results of our experiments with the cytoplasmic ribosome inhibitor cycloheximide also revealed that the synthesis of gln-cys and arg-cys is likely the result of an enzymatic reaction as opposed to ribosomal peptide synthesis. The rapid linear accumulation of the dipeptides in the presence of cycloheximide would suggest that the N-limited cells are poised to enzymatically synthesize these peptides in the event of $\mathrm{N}$ availability. The burst of gln-cys accumulation observed at the earliest time point in response to ammonium, which does not occur when the inhibitor is added, is suggestive of an initial up-regulation of a biosynthetic enzyme. One class of enzymes responsible for the synthesis of small peptides is known as the non-ribosomal peptide synthases (NRPS; Schwarzer et al. 2003). Little is known about NRPS enzymes in marine phytoplank- ton. Alternatively these dipeptides might be formed through the action of aminoacyl-tRNA synthetases (AARSs), which have been shown in vitro to form the dipeptides arg-cys, isoleucine-cysteine (ile-cys) and valine-cysteine (val-cys) via a mechanism involving the interaction of cysteine with the charged ArgRS, IleRS, and ValRS, respectively (Jakubowski 1995). The constitutive nature of AARS enzymes is consistent with our observation that de novo synthesis of enzymes is not required for dipeptide synthesis.

Cyanophycin, an insoluble polymer of repeating aspartic acid-arginine dipeptide dimers, is used for $\mathrm{N}$ storage in some photosynthetic prokaryotes (Allen \& Weathers 1980). It has also been observed to accumulate following $\mathrm{N}$ additions to $\mathrm{N}$-starved cells (Maheswaran et al. 2006), and it can accumulate to levels that are up to between 8 and $16 \%$ of the cell's mass (Allen et al. 1980). In contrast, we found that the dipeptides measured here account for no more than $0.4 \%$ of an Emiliania huxleyi cell on a mass basis.

While these dipeptides are not accumulated to the same extent as cyanophycin in photosynthetic prokaryotes, the direct accumulation of arg-cys and gln-cys constituted a significant storage of $\mathrm{N}$ in one of the Emiliania huxleyi strains examined in the present study. Other N-containing compounds that have been hypothesized to serve as a store of $\mathrm{N}$ in E. huxleyi, glycine betaine and homarine, only accounted for $\sim 0.05 \%$ of the total $\mathrm{N}$ in $\mathrm{N}$-sufficient continuous cultures (CCMP 378 ; Keller et al. 1999). The total $\mathrm{N}$ in arg-cys and gln-cys in P-limited batch cultures of Strain 373 constituted nearly $3 \%$ of the total cellular $\mathrm{N}$ (Table 1). This corresponds to roughly $10 \%$ of the total $\mathrm{N}$ measured in an N-limited cell. It is arguable that since these percentages in Strain $373(3$ to $10 \%)$ are similar to the amount of nitrogen associated with major $\mathrm{N}$ pools, such as total $\mathrm{N}$ in nucleic acids in many algal species (Lourenco et al. 1998), the dipeptides do play a significant storage role. Furthermore, given that roughly $43 \%$ of the total $\mathrm{N}$ in P-limited cells is proteinaceous (based on the sum of $\mathrm{N}$ in individual amino acids), dipeptide $\mathrm{N}$ represented $>7 \%$ of the proteinaceous N. A similar calculation for Strain 382-1 revealed that only $1 \%$ of the total proteinaceous $\mathrm{N}$ was present as dipeptides. Thus, it would appear that the dipeptides are less important for N storage in Strain 3821 than in Strain 373. Strain 373, isolated from the Sargasso Sea, may have developed an ability to store nitrogen in this form as a strategy to survive in a mostly oligotrophic environment, whereas Strain 382-1, a coastal isolate, may only rarely encounter a low $\mathrm{N}$ environment and therefore has less of a need for an $\mathrm{N}$-storage strategy.

A better understanding of the role of these dipeptides in nitrogen assimilation may provide clues as to why Emiliania huxleyi is so successful even under 
N-limiting conditions (Lessard et al. 2005), where they have no previously identified competitive advantage (Riegman et al. 2000). Further investigation into whether other algal species utilize these dipeptides to store $\mathrm{N}$ or to chelate excess $\mathrm{Cu}$ will be important in understanding their role and distribution in the field (Dupont et al. 2006).

Acknowledgements. We thank B. Palenik and D. Landry for providing us with the Emiliania huxleyi strain used in the present paper and C. Kearns for performing the $\mathrm{CN}$ analyses. We acknowledge support from NSF Chemical Oceanography (OCE 0451781) and thank the Cornell NSF Advance leadership for an internal award to B.A.A. Support for H.K. was also provided by the Cornell University Biogeochemistry and Biocomplexity Initiative. We also thank our 3 anonymous reviewers for their helpful comments.

\section{LITERATURE CITED}

- Ahner BA, Wei LP, Oleson JR (2002) Glutathione and other low molecular weight thiols in marine phytoplankton under metal stress. Mar Ecol Prog Ser 232:93-103

Allen MM, Weathers PJ (1980) Structure and composition of cyanophycin granules in the cyanobacterium Aphanocapsa 6308. J Bacteriol 141:959-962

Allen MM, Hutchison F, Weathers PJ (1980) Cyanophycin granule polypeptide formation and degradation in the cyanobacterium Aphanocapsa 6308. J Bacteriol 141: 687-693

Brand LE, Sunda WG, Guillard RRL (1986) Reduction of marine phytoplankton reproduction rates by copper and cadmium. J Exp Mar Biol Ecol 96:225-250

Brown CW, Yoder JA (1994) Coccolithophorid blooms in the global ocean. J Geophys Res 99:7467-7482

Bruhn A, LaRoche J, Richardson K (2010) Emiliania huxleyi (Prymnesiophyceae): nitrogen genes and their expression in response to external nitrogen sources. J Phycol 46: 266-277

Chen YM, Ferrar TS, Lohmeir-Vogel E, Morrice N and others (2005) The PII signal transduction protein of Arabidopsis thaliana forms an arginine-regulated complex with plastid N-acetyl glutamate kinase. J Biol Chem 281:5726-5733

> Dortch Q, Clayton JR Jr, Thoresen SS, Ahmed SI (1984) Species differences in accumulation of nitrogen pools in phytoplankton. Mar Biol 81:237-250

> Dupont CL, Ahner BA (2005) Effects of copper, cadmium, and zinc on the production and exudation of thiols by Emiliania huxleyi. Limnol Oceanogr 50:508-515

- Dupont CL, Nelson RK, Bashir S, Moffett JW, Ahner BA (2004) Novel copper-binding and nitrogen-rich thiols produced and exuded by Emiliania huxleyi. Limnol Oceanogr 49: 1754-1762

Dupont CL, Moffett JW, Bidigare RR, Ahner BA (2006) Distributions of dissolved and particulate biogenic thiols in the subartic Pacific Ocean. Deep-Sea Res I 53:1961-1974

> Dyhrman ST, Palenik B (2003) A characterization of ectoenzyme activity and phosphate-regulated proteins in the coccolithophoride Emiliania huxleyi. J Plankton Res 25: 1215-1225

Holligan PM, Fernandez E, Aiken J, Balch WM and others (1993) A biogeochemical study of the coccolithophore Emiliania huxleyi in the North Atlantic. Global Biogeochem Cycles 7:879-900

Inokuchi R, Kuma K, Miyata T, Okada M (2002) Nitrogen- assimilating enzymes in land plants and algae: phylogenic and physiological perspectives. Physiol Plant 116:1-11

Jakubowski H (1995) Synthesis of cysteine-containing dipeptides by aminoacyl-tRNA synthetases. Nucleic Acids Res 23:4608-4615

Keller MD, Kiene RP, Matrai PA, Bellows WK (1999) Production of glycine betaine and dimethylsulfoniopropionate in marine phytoplankton. II. N-limited chemostat cultures. Mar Biol 135:249-257

> Lessard EJ, Merico A, Tyrrell T (2005) Nitrate:phosphate ratios and Emiliania huxleyi blooms. Limnol Oceanogr 50: 1020-1024

> Llacer JL, Contreras A, Forchhammer K, Marco-Marin C and others (2007) The crystal structure of the complex of P-II and acetylglutamate kinase reveals how P-II controls the storage of nitrogen as arginine. Proc Natl Acad Sci USA 104:17644-17649

Lourenco SO, Barbarino E, Marquez UML, Aidar E (1998) Distribution of intracellular nitrogen in marine microalgae: basis for the calculation of specific nitrogen-toprotein conversion factors. J Phycol 34:798-811

> Maheswaran M, Ziegler K, Lockau W, Hagemann M, Forchhammer K (2006) P-II-regulated arginine synthesis controls accumulation of cyanophycin in Synechocystis sp. strain PCC 6803. J Bacteriol 188:2730-2734

Maurin C, Le Gal Y (1997) Isoforms of glutamine synthetase in the marine coccolithophorid Emiliania huxleyi (Prymnesiophyceae). Comp Biochem Physiol 118B:903-912

Min L, Jin Z, Caldovic L, Morizono H, Allewell N, Tuchman M, Shi D (2008) Mechanism of allosteric inhibition of Naceyl-L-glutamate synthase by L-arginine. J Biol Chem 284:4873-4880

Paasche E (2001) A review of the coccolithophorid Emiliania huxleyi (Prymnesiophyceae), with particular reference to growth, coccolith formation, and calcificationphotosynthesis interactions. Phycologia 40:503-529

Palenik B, Henson SE (1997) The use of amides and other organic nitrogen sources by the phytoplankton Emiliania huxleyi. Limnol Oceanogr 42:1544-1551

Price NM, Harrison GI, Hering JG, Hudson RJ, Nirel PMV, Palenik B, Morel FMM (1988) Preparation and chemistry of the artificial algal culture medium Aquil. Biol Oceanogr 6:443-461

Redfield AC, Ketchum BH, Richards FA (1963) The influence of organisms on the composition of seawater. In: Hill MN (ed) The sea. Interscience Publication, New York, NY, p 26-77

Riegman R, Stolte W, Noordeloos AAM, Slezak D (2000) Nutrient uptake and alkaline phosphatase (EC 3:1:3:1) activity of Emiliania huxleyi (Prymnesiophyceae) during growth under $\mathrm{N}$ and $\mathrm{P}$ limitation in continuous cultures. J Phycol 36:87-96

Schecher WD, McAvoy DC (1998) MINEQL+. A chemical equilibrium modeling program. Environmental Research Software, Hallowell, ME

Schwarzer D, Finking R, Marahiel M (2003) Nonribosomal peptides: from genes to products. Nat Prod Rep 20: $275-287$

Shoaf WT, Lium BW (1976) Improved extraction of chlorophyll $a$ and $b$ from algae using dimethyl sulfoxide. Limnol Oceanogr 21:926-928

> Slocum RD (2005) Genes, enzymes and regulation of arginine biosynthesis in plants. Plant Physiol Biochem 43:729-745

Wei L, Donat JR, Fones G, Ahner BA (2003) Interactions between $\mathrm{Cd}$, and $\mathrm{Cu}$, and $\mathrm{Zn}$ influence particulate phytochelatin concentrations in marine phytoplankton: laboratory results and preliminary field data. Environ Sci Technol 37:3609-3618 
Appendix 1. Additional figures to support the findings of the present article

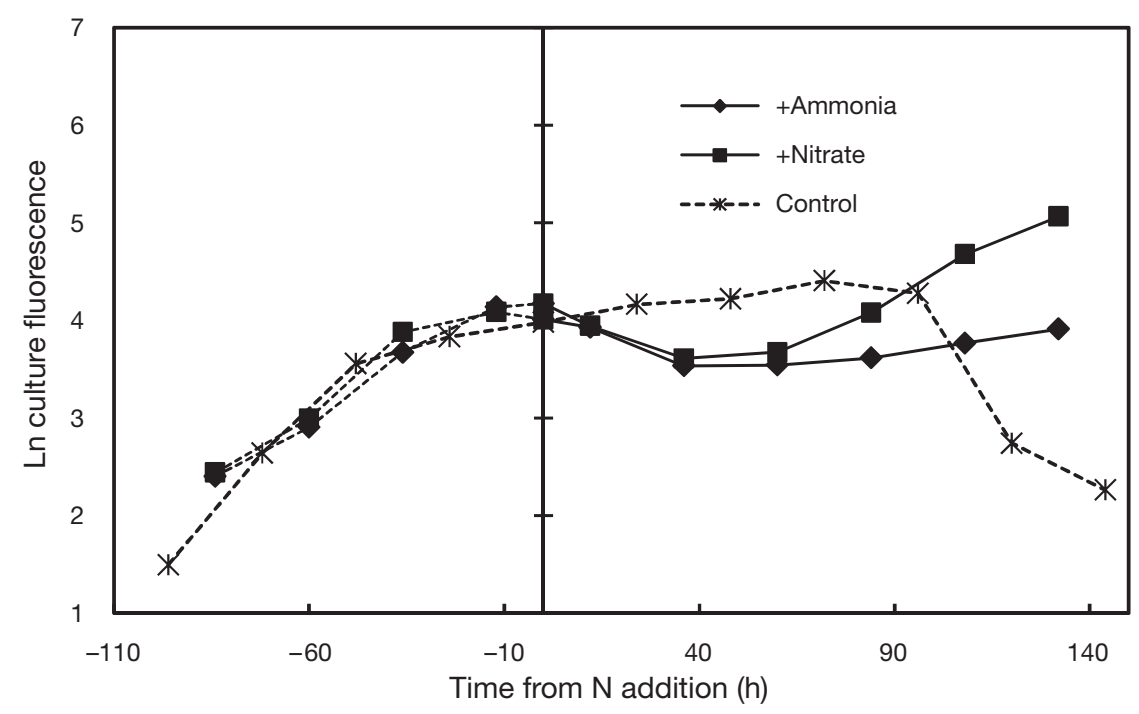

Fig. A1. Emiliania huxleyi. Plot of the natural logarithm of culture fluorescence as a function of time before and after the addition of $100 \mu \mathrm{mol} \mathrm{l} \mathrm{l}^{-1}$ ammonia and nitrate to N-limit batch cultures of E. huxleyi Strain 373. A control to which no $\mathrm{N}$ was added is shown continuing as a dotted line past $t=0$

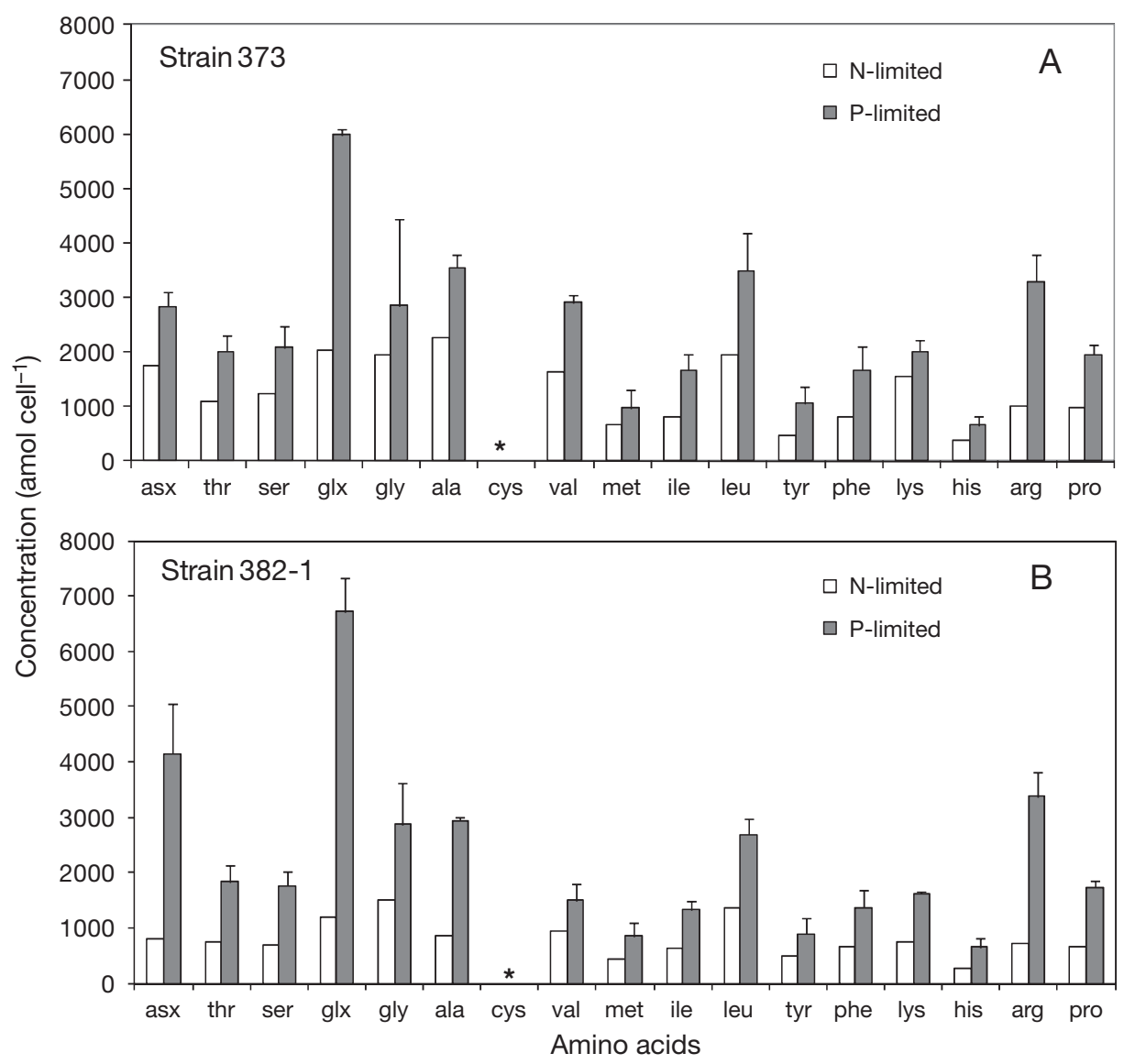

Fig. A2. Emiliania huxleyi. Amino acid concentrations in N- and P-limited E. huxleyi Strain 373 (A) and Strain 382-1 (B). Cysteine concentration is not measurable with this technique as it is destroyed during protein hydrolysis (indicated by asterisks on the graph). Glx represents the sum of glutamate (Glu) and glutamine (Gln), and Asx represents the sum of asparagine (Asn) and aspartic acid (Asp), as described in the 'Materials and methods'. N-limited data were not replicated, whereas the P-limited concentrations represented the average of 2 analyses, with the error bars representing the range of the measured values 